\title{
Research on the Reform of College Entrance Examination Content under the Background of New College Entrance
}

\author{
Ying Bai \\ Fujian Normal University, School of Education, 68, Xuefu North Road, Fuzhou 350117, China
}

\begin{abstract}
Since the reform of the new college entrance examination, the reform of the college entrance examination content has achieved certain results, but there are still problems in the connection of basic education and higher education, the relationship between school teaching and the college entrance examination, knowledge selection and ability examination. The reform of the content of the college entrance examination can solve the problems in the reform by clarifying the educating nature of the content of the college entrance examination, improving the guidance of the content of the college entrance examination, and enhancing the scientificity of the content of the college entrance examination.
\end{abstract}

Key words: College entrance examination content reform; Basic education; Higher education

Publication date: April, 2021; Publication online: 30 April, 2021

*Corresponding author: Ying Bai, 1774380617@qq.com

In 2014, the State Council issued the "Implementation Opinions of the State Council on Deepening the Reform of the Examination and Enrollment System" (hereinafter referred to as the "Implementation Opinions"), marking the official start of a new round of college entrance examination reform. The "Implementation Opinions" clearly proposes to deepen the reform of the content of the college entrance examination, according to the talent selection requirements of universities and the national curriculum standards, scientifically design the content of the propositions, enhance the basic and comprehensive nature, and focus on the examination of students' independent thinking and the use of knowledge to analyze and solve problems ability ${ }^{[1]}$. The "Implementation Opinions" pointed out the direction for the reform of the content of the college entrance examination. With the progress of the "Implementation Opinions", the reform of the college entrance examination content has achieved certain results, but there are still some problems that hinder the progress of the reform.

\section{Problems to be solved in the reform of college entrance examination content}

The content of the college entrance examination is a direct manifestation of the national will to select and cultivate talents, and it is the core link of the college entrance

examination system that reflects the national will[2]. The content of the college entrance examination affects the reliability and validity of talent selection and is the most critical part of the college entrance examination. By reforming the content of the college entrance examination, on the one hand, the content of the exam can be improved and the scientificity of the content of the exam can be improved; on the other hand, it can better realize the selection function of the college entrance examination and select talents required by the country, society, and higher education. However, there are some problems in the actual reform of the content of the college entrance examination, which hinder the education and selection of talents. The reform of the content of the college entrance examination must pay attention to these existing problems and solve these problems in order to better improve the content and promote the effective function of the college entrance examination.

1.1 The problem of connection between basic education and higher education

First of all, basic education and higher education belong to the education system, and there is a certain connection between the two. Basic education and higher education belong to different stages of education. Basic education, also known as "national basic education", is an education to implement basic cultural knowledge for citizens, an education to improve the 
basic qualities of citizens, and an education to lay a solid foundation for further studies or job training ${ }^{[3]}$. The object of basic education is the immature children and teenagers in body and mind, and the socialist builders and successors with all-round development of morality, intelligence, physique, beauty and labor should be trained. Basic education emphasizes "basicity", focuses on cultivating students' basic knowledge and basic abilities, and lays the foundation for students' future development, and belongs to general education. Higher education is a professional education based on general education (or basic education) ${ }^{[4]}$. The target of higher education is young people whose physical and mental development is basically mature, and what we need to train are leading, innovative, and compound professionals who serve and lead social development. Higher education emphasizes "professionalism", focusing on cultivating students a certain type of knowledge and abilities, and laying the foundation for students to engage in a certain field in the future. Different stages of education have different attributes and characteristics, and have their own functions. However, from the perspective of the whole education system, there is a close relationship between basic education and higher education. Basic education has cultivated and delivered a large number of talents for higher education and laid the foundation for the normal operation of higher education. As a higher level of education above basic education, higher education can train high-level teachers with professional qualities for the development of basic education, and can innovate knowledge to enrich the teaching content of basic education. Therefore, basic education and higher education can not be separated or ignored the connection between them.

Secondly, the college entrance examination, as a selective examination, is an important way for colleges and universities to select talents. As an important basis for college enrollment, college entrance examination scores determine whether students are qualified for higher education. The selection function of the college entrance examination is embodied in that it helps colleges and universities select candidates who have certain knowledge and ability and are suitable for higher education from the group of students participating in the college entrance examination. The knowledge and abilities that candidates need to possess are inseparable from what kind of people higher education wants to cultivate. The examinee's amount of knowledge and ability level must reach a certain standard, which is a prerequisite for the examinee to accept higher education. To enable candidates to master a certain amount of knowledge and have a higher level of ability, we need to rely on high school education. Through high school education, students' knowledge and abilities in all aspects are improved to be qualified for higher education. At the same time, the college entrance examination is also regarded as a final exam for high school education to test students' knowledge and ability in high school. The college entrance examination has realized the connection between basic education and higher education by selecting talents for colleges and universities. This kind of connection is internal and substantial, and its external manifestation is in the content of the college entrance examination. Through the design of the content of the college entrance examination, the knowledge and ability of high school are connected with the knowledge and ability of higher education. This kind of connection in content will more effectively realize the selection function of the college entrance examination, and make the scores of the college entrance examination more reliable and valid.

At present, there is a phenomenon that the content of college entrance examination pays too much attention to high school education and neglects higher education. The content of the college entrance examination does not connect basic education with higher education, but separates the two, taking the examination of students' high school knowledge and ability as the whole mission. As a result, students' learning may be more confined to high school knowledge, and may not have the knowledge and abilities necessary for higher education. As a result, the college entrance examination will not be able to select truly suitable students for colleges and universities, which will affect the efficiency and education of higher education. quality. Therefore, the content of college entrance examination must pay attention to the connection between basic education and higher education, and regard them as two closely related parts in a whole, so as to give full play to the role of talent selection and promote the cooperative education of basic education and higher education.

\subsection{The problem of relationship between school teaching and college entrance examination}

The ideal relationship between school teaching and college entrance examination is that teaching is carried out orderly, and college entrance examination is a way to test teaching results. School teaching plays an important role in the process of personnel training. Teaching achieves the goal of educating people by clarifying the teaching objectives, highlighting the important and difficult points of teaching, choosing teaching 
methods, and designing the teaching process. It is a purposeful, planned and organized form of activity. This relatively complete and scientific process of teaching will provide teachers with guidance for effective teaching. In addition, teaching is an activity that pays attention to the process. It requires teachers and students to participate in it, taking students as the center, so that students can develop in all aspects of the process of participating in teaching activities. Teaching can integrate knowledge imparting, cultivating ability and improving quality, and build a modern innovative talent training system, which can maximize the role of educating people and better achieve the goal of educating people. The college entrance examination is a means and a method to test students' knowledge mastery, ability development, emotional attitudes and values. It emphasizes the achievement of students in all aspects after completing three years of high school education, and focuses on the results. Moreover, the selection of the content of the college entrance examination is based on the knowledge of the high school stage in order to more effectively examine the learning situation of the students. However, due to issues such as test time and test paper length, the content of the college entrance examination usually only involves part of high school teaching, focusing on certain knowledge and ability. Therefore, school teaching is the main body and the core, undertaking the important task of personnel training, and the college entrance examination is the auxiliary, is the means to test the quality of personnel training.

At present, there is a phenomenon of putting the cart before the horse in school teaching and college entrance examination. The college entrance examination is a "high competition, high stakes, high risk" exam. At the same time, the college entrance examination is also a large-scale examination involving a large number of people, with a wide range of influence, and the decisions made based on the examination results will affect the distribution of significant interests and have an important impact on both individuals and society ${ }^{[5]}$. For students, college entrance examination scores determine whether students are eligible for higher education and what kind of higher education resources they obtain. For parents, the college entrance examination is an important way to promote their children's upward social mobility. For schools, students' college entrance examination results determine the school's enrollment rate, and affect the acquisition of follow-up education resources and high-quality students. The college entrance examination involves many stakeholders, and due to the high stakes of the college entrance examination, all stakeholders place it in an extremely important position and pay great attention to it. This kind of excessive attention to the college entrance examination has affected the normal school teaching. There is an abnormal relationship between education and college entrance examination. The college entrance examination has become the baton of school teaching, the exam determines the teaching, the teaching process revolves around the test questions, and the teaching content is formulated according to the test outline. Teaching is led by the nose by the college entrance examination, lack of vividness, flexibility, creativity, and lost the heart of educating people.

The reform of the content of the college entrance examination must pay attention to the relationship between school teaching and college entrance examination, straighten out the relationship between teaching and examination, and clarify the guiding role of the college entrance examination on teaching, not the leading role. Through the design and reform of the content of the college entrance examination, the reform of high school education methods can be promoted, and the education concept based on student development can be regained to promote the improvement of students' comprehensive quality and truly achieve morality. Moreover, the reform of college entrance examination content will help to promote the effective connection between teaching and college entrance examination, change the problem that learning is determined by examination, overcome the problem that examination content is teaching content and learning content, and reverse the utilitarian tendency of education. Conversely, if the reform of the content of the college entrance examination does not pay attention to the relationship between teaching and examination, the problem of "teaching for examination" in the actual education process cannot be solved.

\subsection{The Problem of Knowledge selection and ability examination}

The key to the reform of the content of the college entrance examination is the content, which must start from the content itself. The content of the examination is the basis for testing the results of students' learning. Whether the definition of the content to be tested is clear and reasonable directly affects the validity of the college entrance examination and the scientific nature of talent selection ${ }^{[6]}$. The content of the college entrance examination judges the overall learning situation of the students in the three years of high school by examining 
the knowledge and ability of the students, and selecting students suitable for higher education based on this As far as the college entrance examination for a certain subject is concerned, the examination of the subject consists of a series of questions containing certain knowledge and ability requirements based on a certain design. The material information, knowledge and ability to be tested together constitute the content of the examination. Except for the set situation, that is, the provided materials, the core part of the exam content is what kind of knowledge and ability are tested. The choice of knowledge and ability should be based on the high school curriculum standards and the needs of talent cultivation in Colleges and universities, but the high school curriculum standards are the main ones. According to the requirements of high school curriculum standards, the total amount of knowledge that students need to learn and master in three years of high school is huge, and the ability to develop is multi-dimensional. Therefore, the content of the examination has its own choice and emphasis. The examination content usually chooses the core and key knowledge of high school to test the students' necessary ability.

In the actual operation process, the content of the college entrance examination is "bias", which causes the college entrance examination to not be able to effectively perform the selection function. Proposition experts usually need to strictly control the repetition rate to avoid the phenomenon of multiple examinations of the same knowledge points in the same exam paper or the same questions in previous years. Therefore, the content of each test has been adjusted. But sometimes it overemphasizes the repetition rate and pursues innovation, so the mission problem goes on the wrong road. By selecting some rare and difficult knowledge points, the proclaimers can check the students', knowledge and ability development, and avoid the problem of high repetition rate. This leads to the alienation of the examination content, towards the direction of "bias". The content of the exam is no longer to test the students' learning, but to stump the students. Guided by this, the test content has problems in choosing the knowledge points to be examined. Instead of choosing knowledge with disciplinary value and educational value, it chooses outdated and partial knowledge. This kind of deviation in the choice of knowledge affects the examination of ability. Partial and old knowledge cannot effectively test the development of students' abilities, especially the innovation ability and the core competence of the subject.
This reduces the effectiveness of the content of the examination and makes it impossible to select real talents.

The content reform of college entrance examination must pay attention to the choice of knowledge and ability examination. What kind of knowledge to choose will not only guide school teaching, but also affect ability testing. The deviation in the process of choosing knowledge will mislead teaching and affect school education. At the same time, the ability of students cannot be accurately tested, which reduces the validity of test papers and cannot effectively distinguish students. Therefore, the content of the reform process of college entrance examination needs to be clear about what kind of knowledge to choose and what kind of ability to test. The content of the examination should choose knowledge with more subject value and educational value, and examine the ability of key subjects, so as to give full play to the selection function of the college entrance examination.

\section{Countermeasures to solve the problem}

In the process of reforming the content of the college entrance examination, the problems of the link between basic education and higher education, the relationship between school teaching and the college entrance examination, the problems of knowledge choice and ability examination will all hinder the reform process and affect the reform effect. Therefore, it is necessary to put forward corresponding solutions to the problems existing in the reform of the content of the college entrance examination in order to realize the effectiveness of the reform of the content of the college entrance examination.

\subsection{Clarify the educational nature of the content of the college entrance examination}

The content of the college entrance examination not only helps the college entrance examination to better play the role of selecting talents for colleges and universities, but also has the role of educating people. The content of the college entrance examination can examine the development of students' knowledge and ability, and help students recognize the deficiencies in self-learning. At the same time, it also contains certain values, which can have a positive and positive impact on students. This kind of educational function of the content of the college entrance examination will help the connection between basic education and higher education. Clarifying the educative nature of the content of the college entrance examination means that you can jump out of the inherent thinking paradigm, and do not emphasize knowledge 
too much, but to promote human development as an observation point. This makes it possible to choose some content with strong educational characteristics during the reform of the college entrance examination content, instead of strictly sticking to the knowledge required by the high school curriculum standards. This also provides an opportunity to add some knowledge of higher education to the examination content. Appropriately adding the content of higher education stage in the examination content can promote the connection between basic education and higher education, and can also improve the validity of talent selection. Although basic education and higher education are not the same in terms of educational objects, teaching content, curriculum settings, and training objectives, their operation processes are relatively independent. But basic education and higher education have a common function-educating people. They can cause a series of changes to students during their school years, including cognition, behavior, emotion, attitude and other aspects. Taking the common point of education as the cornerstone, choosing part of the education knowledge common to basic education and higher education can not only promote the content of the college entrance examination to better link basic education and higher education, but also highlight the educational nature of the content of the college entrance examination.

\subsection{Improving the guidance of the content of the college entrance examination}

The content of college entrance examination plays a guiding role in school teaching. As a high-stakes and large-scale selective examination, the college entrance examination has always attracted attention, and the content of the college entrance examination has naturally become the focus. For different purposes, people from all walks of life will interpret and analyze the contents of the college entrance examination. For basic education schools, through the analysis of the content of the college entrance examination, the important and difficult points and question types of the exam can be grasped, so that teachers can find deficiencies in teaching and provide guidance for further improvement. This guiding role of the content of the college entrance examination can affect the process of school teaching and education. Therefore, it is necessary to enhance the guidance of college entrance examination content and provide direction for teaching and education. First of all, we should design the content of the test. The content of the exam can choose materials that are closely related to life and the times, and create specific situations to stimulate students' flexibility and creativity in thinking. Secondly, standardize the process of setting test questions. It is necessary to make clear the examination objectives, key points and methods, and strengthen the design of examination questions for students' ability to analyze and solve problems. Moreover, we should change the single scoring method and combine multiple scoring methods. Different examination subjects and types have different characteristics, so we should adopt the appropriate scoring method to improve the scientificity of examination scores. In addition, through the design of the content of the college entrance examination, the selection of materials, the setting of test questions, and the way of grading, the promotion of students' health and allround development is taken as the starting point and foothold, and scientific integration into the requirements of the comprehensive cultivation of moral, intellectual, physical, art and labor, promoting the implementation of core literacy and boosting the development of liberal education ${ }^{[7]}$. The above measures are conducive to enhancing the guiding role of the content of the college entrance examination, guiding school education to place moral education, physical education, aesthetic education, and labor education in the same important position as intellectual education, and guiding students to grow in an all-round way.

\subsection{Enhance the scientific nature of the content of the college entrance examination}

The scientific nature of the content of the college entrance examination affects the validity of talent selection. If the content of college entrance examination is less scientific, it can not examine the students' real knowledge and ability development, nor can it select suitable talents for colleges and universities. Therefore, we must pay attention to the scientific nature of the content of the college entrance examination. First of all, according to the examination standard proposition, standardize the proposition process. Generally speaking, the examination standard is scientific, instructive and normative, which is the basis of college entrance examination proposition. The propositional person must take the examination standard as the basis, according to the propositional step proposition. The topic should examine the students from the following aspects: one is a comprehensive examination of basic knowledge; the second is to focus on the examination of the main content, especially the examination of the content that is connected with university teaching; the third is to focus on the use of basic methods; the fourth is to focus on Examination of basic experimental operations ${ }^{[8]}$. Secondly, the goal of the 
test is clearly defined in the proposition process. The propositional person must examine what kind of knowledge, ability of the student explicitly. According to the content of knowledge, the Economic Development and Cooperation Organization divides knowledge into four types: declarative knowledge, principle knowledge, procedural knowledge and empirical knowledge. Each kind of knowledge constitution, the emphasis are all different, has the different characteristic. The type of knowledge selected for the college entrance examination and the proportion of each type of knowledge will affect the content of the examination. In addition, different types of knowledge can help students master different abilities. This also means that the ability to choose different types of knowledge as the content of the examination is different and focused. Therefore, when propositioning, we should clearly examine the objectives, pay attention to the types of knowledge, and the relationship between different types of knowledge and ability tests.

The reform of the content of the college entrance examination is a key part of the reform of the new college entrance examination. The effect of the reform of the content of the college entrance examination affects the process of the reform of the college entrance examination. The problems that arise in the reform of the formal college entrance examination content and the timely resolution of these problems can ensure the smooth progress of the college entrance examination reform.

\section{References}

[1] State Council. Implementation opinions of the State Council on deepening the reform of examination and enrollment system [EB/OL]. http://www.moe.gov.cn/jyb_xxgk/moe_1777/moe_1778/201 409/t20140904_174543.html,2014-09-04.
[2] Wu yangshuo, Zhao Xuan, Zhao Jingyu, Guo Xueheng. Practice and exploration of content reform of college entrance examination under the background of comprehensive cultivation of morality, intelligence, Physique, art and labor[J]. Curriculum•teaching materials॰teaching methods, 2020,40(5):126-131.

[3] Gu Mingyuan .Education Dictionary[M]. Shanghai: Shanghai Education Press, 1998:627.

[4] Pan Mao yuan. New higher education[M]. Beijing: Beijing Normal University Press,2012:5.

[5] Zheng Ruoling, Chen Weifeng. The negative aftereffects of large-scale high-stakes examinations: taking imperial examinations and college entrance examinations as examples[J]. Journal of Central China Normal University (Humanities and Social Sciences Edition),2013,52(1):147145.

[6] Lai Xiulong. The Foreign Experience and Enlightenment of the Reform of College Entrance Examination[J]. Contemporary Educational Science,2017(12):50-55+59.

[7] Sun Haibo. In-depth study and implementation of the spirit of the Fourth Plenary Session of the 19th Central Committee of the Communist Party of China, and comprehensively deepen the reform of college entrance examination content[J]. China Examinations,2020(01):1-6.

[8] Ren Zichao, Zhao Xuan, Chen Ang. Deepening the reform of the content of the college entrance examination and boosting the development of quality education — the key problems and solutions in the reform of the new college entrance examination[J]. China Higher Education Research, 2019(1): 38-42. 